\title{
Integration of a Photovoltaic System with an Electric Heat Pump and Electrical Energy Storage Serving an Office Building
}

\author{
Carlo Roselli $^{*}$, Francesco Tariello ${ }^{2}$, Maurizio Sasso ${ }^{3}$ \\ ${ }^{1}$ Engineering Department, University of Sannio, Piazza Roma 21, Benevento, Italy \\ e-mail: carlo.roselli@unisannio.it \\ ${ }^{2}$ Department of Medicine and Health Sciences - Vincenzo Tiberio, University of Molise, Via Francesco \\ De Sanctis, 1, 86100 Campobasso CB, Italy \\ e-mail: francesco.tariello@unimol.it \\ ${ }^{3}$ Engineering Department, University of Sannio, Piazza Roma 21, Benevento, Italy \\ e-mail: sasso@unisannio.it
}

Cite as: Roselli, C., Tariello, F., Sasso, M., Integration of a Photovoltaic System with an Electric Heat Pump and Electrical Energy Storage Serving an Office Building, J. sustain. dev. energy water environ. syst., 7(2), pp 213-228, 2019, DOI: https://doi.org/10.13044/j.sdewes.d6.0248

\begin{abstract}
A renewable-based system able to meet pure electric, space heating and cooling loads of a small office building located in Southern Italy is evaluated here. The proposed energy conversion system is based on a photovoltaic plant, an electric-driven heat pump and electrical energy storage. Energy and environmental performance of this system has been evaluated by means of a dynamic simulation software changing photovoltaic nominal power (4.5-7.5 $\mathrm{kW})$, battery capacity $(3.2-9.6 \mathrm{kWh})$, and reference electrical system. The aim of the paper is the energy and environmental comparison on monthly, as well as, on yearly basis between the proposed system and the reference conventional system. The conventional system is based on the power grid, a natural gas fired boiler and an electric-driven chiller. The analysis here reported shows how monthly variation of electric reference system, due to different monthly Italian electricity mix production, influences the energy and environmental performance of the solar-based system. The proposed system guarantees high primary energy saving and equivalent carbon dioxide emissions reduction up to about $93 \%$.
\end{abstract}

\section{KEYWORDS}

Photovoltaic, Electric heat pump, Electrical energy storage, Energy saving, Carbon dioxide emissions reduction, Renewable energy.

\section{INTRODUCTION}

In 2012, space cooling and heating final energy demand in domestic and service sectors for EU28 was about 3,481 TWh, which corresponds to $27.1 \%$ of total final energy demand [1]. In particular, in EU28 tertiary sector, space heating requires $681 \mathrm{TWh}$ while for space cooling the demand is $105 \mathrm{TWh}$. In details Italy presents a final energy demand for space cooling and heating in service sector of $92.3 \mathrm{TWh}$, of which $67.4 \%$ is for space heating and $31.6 \%$ for space cooling [1]. High energy demand in service sector due to

\footnotetext{
${ }^{*}$ Corresponding author
} 
space cooling and heating demands has led to an increasing attention to the saving of primary energy and to the reduction of the related greenhouse gas emissions.

Different ways could be considered to obtain these results: in the last decade great efforts have been concentrated in the use of renewable technologies. Solar thermal Heating and Cooling (SHC) plants have been evaluated for tertiary field applications [2] considering adsorption [3] or absorption chillers [4]. A solar-activated system to meet cooling and heating loads could be made up with the introduction of a Photovoltaic (PV) plant feeding an Electric-driven Heat Pump (EHP). In 2016, the cumulative installed power of PV panels has been reached in Italy the value of $19.3 \mathrm{GW}$. PV electricity delivered in 2016 was $22.1 \mathrm{TWh}$, corresponding to $7.2 \%$ of global Italian electricity final demand [5]. In 2016, a percentage equal to18.9\% of electricity delivered by PV plants was used on-site and the remaining share was exported to the power grid [6].

The above reported data on Italian PV electricity use show that the on-site exploitation of electric energy is very low, and raises attention to the technologies able to increase it. One of these technologies is the EHP that allows to cover space cooling and heating demands in buildings. Different applications of PV-EHP system, on the basis of the end user (office, commercial, school, residential, etc.), could be considered.

Huang et al. [7] presented an energy and economic analysis both for PV-based and solar thermal-based systems to meet heating and cooling demands of residential building in a hot-summer and cold-winter zone in China. PV plant has a peak power of $15.6 \mathrm{~kW}$, while the rated cooling capacity of the two electric heat pumps is $28 \mathrm{~kW}$ and $65 \mathrm{~kW}$ respectively, and the rated heating capacities are $30 \mathrm{~kW}$ and $69 \mathrm{~kW}$. The average nominal Energy Efficiency Ratio (EER) values were taken equal to 2.82 for cooling operating mode and Coefficient of Performance (COP) was chosen equal to 3.11 for heating operation. An annual primary energy saving of $30.7 \%$ is achieved by PV-based system, while the payback time is lower than 7 years.

Bilir and Yildirim [8], a school building located in Izmir (Turkey) was taken into consideration. An energy, economic and environmental analysis of PV-based system was carried out. This system is used to satisfy pure electric load as well as heating and cooling demand by means of an EHP. The authors considered two PV plant sizes $(36-53 \mathrm{~kW})$. On a yearly basis, the coverage ratio is $110 \%$ for Case $1(36 \mathrm{~kW})$ and $162 \%$ for Case 2 (53 $\mathrm{kW}$ ). A simple payback of 7.9 years and 7.6 years, for Case 1 and Case 2 respectively, has been obtained. The energy payback time for both systems has been found as 5 years, while the greenhouse gas emission payback time is 2.7 years when compared with coal-based power plant electricity and 5.9 years when compared with natural gas based power plant electricity.

Solano et al. [9] analyse the electricity demand for an EHP interacting with a PV plant serving a commercial building located in Quito and Guayaquil (Ecuador). The PV system has been sized to meet electric energy required by EHP. For both locations, depending on the orientation of the building, different PV sizes (30-154 kW) were considered. Results show that the PV plant could guarantee an annual economic saving higher than $50 \%$ with a simple payback time between 10 and 30 years.

In [10], the authors use a cost-optimal method to design a PV plant serving a farm hostel located in Enna (Italy). Energy demand considered here includes space heating and cooling served by an air to water heat pump, as well as appliances, lighting and office devices. In this paper the solution proposed can guarantee a lifecycle cost reduction of $11 \%$ and a corresponding primary energy saving of $67 \%$, with respect to the reference plant without renewable contribution.

To further increase the on-site use of electricity available from PV panels, different energy storage technologies could be considered. The main solutions could be based on a thermal energy storage interacting with an EHP or on an Electric Energy Storage (EES) linked to PV plant. 
To improve the flexibility of PV-based system Romaní et al. [11] investigated a PV plant coupled to a heat pump supplying heat to a radiant wall as a system to reduce the imported electricity from the grid for heating and cooling purpose of buildings. The authors proposed the introduction of a radiant wall working as a thermal storage system allowing the accumulation of the PV output and, thus, the peak load shifting. Results derived from the analysis performed by the authors showed that charging the wall with solar energy resulted in higher overall energy use of the heat pump, while the imported grid energy was significantly reduced, thanks to the improvement of on-site use of PV electricity.

Schwarz et al. [12] focused their attention on a residential quarter located in Southern Germany with a PV-based system $(36-73 \mathrm{~kW})$. The authors evaluate how electric heat pumps as well as thermal and electrical energy storages can improve on-site use of PV electricity. The paper analyses the impact of different tariffs (unitary standard fixed, dynamic, and a capacity pricing scheme) on the investment and operation decisions and also the interaction of renewable system with the external power grid. Considering different scenarios it appears that the on-site use of electricity varies between 58 and $75 \%$. Furthermore, the authors investigate how the demand side flexibility can improve PV contribution finding that for each configuration is better to act on thermal energy storage than on electric energy storage.

PV plants are normally grid-connected but to avoid issues to the interaction with the power grid could be interesting to use off-grid plant as investigated by Carriço et al. [13].

Different researchers investigated energy conversion systems serving office buildings based on PV panels that can also integrate battery storage and interact with an EHP [14-22].

In Aguilar et al. [14], an experimental analysis on an air-to-air heat pump unit powered using both a PV plant and the power grid has been performed. The control system gives priority to the renewable plant in order to maximise the on-site use of electricity. PV peak power is $705 \mathrm{~W}$ while EHP has cooling power of $3.52 \mathrm{~kW}$ $(\mathrm{EER}=4.09)$ and heating power equal to $3.81 \mathrm{~kW}(\mathrm{COP}=3.83)$. The plant has been used for an office building with $35 \mathrm{~m}^{2}$ in Alicante (Spain). The solar contribution, defined as the ratio between electricity available from PV and total electric demand of the office, is about $65 \%$.

A PV-based system that integrates an EHP satisfies electric, cooling and thermal loads of a building used for office purpose in Naples (Italy) was investigated in Roselli et al. [15]. This energy conversion system has been evaluated through the dynamic simulation software TRNSYS. Performance on energy, as well as on economic and environmental basis of the system, changing different variables (PV nominal power, panel tilt angle, natural gas and electricity specific price), were evaluated. The proposed system leads to a saving in terms of primary energy and to a lowering of equivalent Carbon dioxide $\left(\mathrm{CO}_{2}\right)$ emissions up to $81 \%$ when matched to a conventional reference system consisting of Italian electric power grid, an electric-driven chiller and a gas-fuelled boiler.

The system introduced in Roselli et al. [15] was subsequently analysed adding electric energy storage [16]. The introduction of battery leads to an abatement of electricity feeding the power grid but the high first cost of this equipment affects the economic results. A further way to improve the on-site use of PV electricity could be the use of a "mobile storage" represented by an Electric Vehicle (EV) as investigated in $[17,18]$ starting from the system proposed in Roselli et al. [15]. In particular in Roselli and Sasso [17], the authors performed an energy and environmental analysis varying PV peak power, EV charging mode and daily distance aiming the increase of on-site use of electricity available from PV plant. The introduction of an EV leads to a higher electricity demand, even if the on-site use of PV electricity improves. 
In Roselli et al. [18], an energy analysis on annual basis of three scenarios based on PV and EHP was considered: the first one without electric energy storage, the second one with an electric energy storage $(9.6 \mathrm{kWh})$ and the third scenario with the introduction of an EV (120 km/day). The analysis was carried out varying only PV plant size. The solution guaranteeing the highest on-site use of renewable electricity was that one characterized by the use of electric energy storage.

Hartmann et al. [19] analysed by means of TRNSYS a system characterized by a PV plant activating an electric-driven chiller that meets electric and cooling demand of a low size office building located in Freiburg (Germany) and Madrid (Spain). The authors reported an economic and energy analysis of the solar system changing PV panel area. The performance improves with PV collecting area reaching a saving of primary energy up to about $40 \%$ for the city of Freiburg and about $60 \%$ for the plant supposed to be located in Madrid.

An analysis performed on experimental and theoretical basis on a system composed by PV collectors $(2.88 \mathrm{~kW})$, an EHP and an EES (250 Ah) has been reported in Izquierdo et al. [20]. EHP with a rated thermal power equal to $6 \mathrm{~kW}$, meets space heating load of a small laboratory built in Spain.

An energy and environmental analysis on a solar-based system has been performed by Izquierdo et al. [21]. The study starts from experimental data of a system consisting of PV modules (2.16 kW), an EES (250 Ah) and an EHP, with a rated thermal power equal to $6 \mathrm{~kW}$, that covers demand for space heating of a lab situated in Spain.

A field test on a system consisting of a stand-alone solar PV system, an EES and an electric-driven chiller has been considered in Huang et al. [22]. The system meets the requirements of a low-energy demand building with an average U-value of the building envelope of $0.22 \mathrm{Wm}^{-2} \mathrm{~K}^{-1}$. The tests on six system layouts were carried out evaluating actual and daily performance. The results show that an improved battery storage size and inverter that integrates Maximum Power Point Tracker (MPPT) technology have to be introduced to increase the performance.

The above reported papers show a focus on simulative or experimental studies of solar activated heating and/or cooling systems for buildings mainly considered for office purpose. The energy conversion systems introduced in these studies are characterized by the presence of an electric-driven heat pump or electric-driven chiller and a PV plant. These papers report the results for specific days, or on seasonal and annual basis. According to the best knowledge of the authors no paper investigates how the monthly variation of power grid mix for such systems can affect the primary energy saving and reduction of $\mathrm{CO}_{2}$ emissions. The approach normally considered in the above reported literature review is based on the introduction of average annual performance factor affecting power grid. The proposed approach can affect the performance of the analyzed systems, and in particular the performance of electric-driven heat pump subsystem. The primary energy linked to this equipment depends not only by outdoor air temperature but also by electricity mix that is not constant but varies on monthly basis.

Hereinafter, a PV field that activates an air to water EHP covering space cooling and heating load of a small office building in Naples (Southern Italy) is analysed on monthly and annual basis evaluating energy and environmental performance parameters. The aim of this paper is to understand how the monthly variation of electric Italian reference power grid efficiency can influence the performance of solar-activated systems. The analysis is carried out analysing two scenarios: the first consisting of PV-EHP system only, while the second is upgraded also by an EES. The importance in introducing lay-out system able to increase on-site use of PV electricity to meet building demand is also analysed in this paper. The reduction of PV electricity feeding the electric grid is an element often underestimated. Indeed the energy policy needs to be oriented towards the improvement of on-site use of electricity available from renewables. Solar based system 
proposed in this paper can guarantee satisfactory saving in terms of primary energy and reduction of equivalent $\mathrm{CO}_{2}$ emissions up to about 93\%. By adding electric energy storage the contribution of external grid, that is always present, can be alleviated.

\section{METHODS}

This paragraph reports the methods put forward to evaluate the Proposed System (PS) based on a PV field, an EHP and an electric energy storage. In particular, two energy indexes to evaluate the on-site use of electric energy available from PS are introduced. Furthermore, an energy and environmental comparison between the solar-PV system and the Reference System (CS), based on electric grid, an electric-activated chiller and a natural gas boiler, are introduced here. Both systems will be described in detail in the following paragraphs.

\section{Proposed system evaluation: Methods}

One of the major problems of grid-connected PV fields is the electricity feeding the power grid that lead to interferences to it (power quality, voltage regulation, etc.). To limit this interaction, an EES could be added to the PV plant. Two indexes highlighting the on-site use of PV electricity could be introduced in Weniger et al. [23]:

- $\quad s$ : ratio between on-site use of electricity available from PV plant and the total that the office requires;

- $d$ : ratio between on-site electricity supplied by PV plant to the office and total delivered by PV plant.

\section{Energy and environmental analysis: Methods}

The energy analysis is based on the comparison of PS and CS introducing Fuel Energy Saving Ratio (FESR) parameter, that compares the primary energy input linked to fossil fuel of the conventional $\left(E_{\mathrm{p}}^{\mathrm{CS}}\right)$ and the proposed $\left(E_{\mathrm{p}}^{\mathrm{PS}}\right)$ systems. FESR can be expressed as eq. (1):

$$
F E S R=\frac{E_{\mathrm{p}}^{\mathrm{CS}}-E_{\mathrm{p}}^{\mathrm{PS}}}{E_{\mathrm{p}}^{\mathrm{CS}}} \times 100
$$

where primary energy input, due to the fossil fuel, needed by conventional and proposed systems is computed introducing [eq. (2) and eq. (3)]:

$$
\begin{gathered}
E_{\mathrm{p}}^{\mathrm{CS}}=E_{\mathrm{p}}^{\mathrm{PP}}+E_{\mathrm{p}}^{\mathrm{B}}=\frac{E_{\mathrm{el}}^{\mathrm{PP}}}{\eta_{\mathrm{el}}^{\mathrm{PP}}}+\frac{E_{\mathrm{th}}^{\mathrm{B}}}{\eta_{\mathrm{th}}^{\mathrm{B}}} \\
E_{\mathrm{p}}^{\mathrm{PS}}=E_{\mathrm{p}}^{\mathrm{PP}}-E_{\mathrm{p}}^{\mathrm{grid}}=\frac{E_{\mathrm{el}}^{\mathrm{PP}}-E_{\mathrm{el}-\mathrm{exp}}^{\mathrm{grid}}}{\eta_{\mathrm{el}}^{\mathrm{PP}}}
\end{gathered}
$$

where the primary energy input is a function of:

- Primary energy $\left(E_{\mathrm{p}}^{\mathrm{PP}}\right)$ linked to electric energy imported from the grid $\left(E_{\mathrm{el}}^{\mathrm{PP}}\right)$ and avoided primary energy $\left(E_{\mathrm{p}}^{\text {grid }}\right)$ related to electric energy exported to power grid $\left(E_{\text {el-exp }}^{\text {grid }}\right)$. The electric energy sent to power grid is computed as a credit to evaluate primary energy input of the PS;

- Primary energy needed by the boiler $\left(E_{\mathrm{p}}^{\mathrm{B}}\right)$ to meet heating load $\left(E_{\mathrm{th}}^{\mathrm{B}}\right)$.

The environmental analysis is performed evaluating equivalent $\mathrm{CO}_{2}$ emissions for proposed $\left(\mathrm{CO}_{2}^{\mathrm{PS}}\right)$ as well as for reference $\left(\mathrm{CO}_{2}^{\mathrm{CS}}\right)$ system. 
The $\mathrm{CO}_{2}$ emissions are estimated introducing $\mathrm{CO}_{2}$ emissions factors. This parameter, identified by $\beta$, is equal to $0.205 \mathrm{~kg} \mathrm{CO}_{2}$ for each $\mathrm{kWh}$ of primary energy, if the energy conversion system is fuelled by natural gas. The emission factor for electric energy imported from power grid $(\alpha)$, is $0.360 \mathrm{~kg} \mathrm{CO}_{2}$ per $\mathrm{kWh}$ of electricity and was evaluated including the contribution of the fossil fuel activated thermo-electric power plants and the renewable systems [24]. Similarly to $F E S R, \Delta \mathrm{CO}_{2}$ can be expressed as:

$$
\begin{gathered}
\Delta \mathrm{CO}_{2}=\frac{\mathrm{CO}_{2}^{\mathrm{CS}}-\mathrm{CO}_{2}^{\mathrm{PS}}}{\mathrm{CO}_{2}^{\mathrm{CS}}} \times 100 \\
\mathrm{CO}_{2}^{\mathrm{CS}}=\mathrm{CO}_{2}^{\mathrm{PP}}+\mathrm{CO}_{2}^{\mathrm{B}}=\alpha \times E_{\mathrm{el}}^{\mathrm{PP}}+\beta \times E_{\mathrm{p}}^{\mathrm{B}} \\
\mathrm{CO}_{2}^{\mathrm{PS}}=\mathrm{CO}_{2}^{\mathrm{PP}}-\mathrm{CO}_{2}^{\mathrm{grid}}=\alpha \times\left(E_{\mathrm{el}}^{\mathrm{PP}}-E_{\mathrm{el}-\exp }^{\mathrm{grid}}\right)
\end{gathered}
$$

\section{BUILDING AND END USER DESCRIPTION}

The building introduced in this study is situated in Naples (Southern Italy), city that is in a climatic zone characterized by 1,034 heating degree days. It is characterized by one floor and by a flat roof, with a floor area of $200 \mathrm{~m}^{2}$, to which corresponds $600 \mathrm{~m}^{3}$ in terms of volume. The envelope characteristics of the building are reported in Table 1, the solar heat gain ( $g$-value) for window is 0.75 . Thirteen people seated and performing light office working are present in weekdays between 9:00 and 13:00 in the morning as well as in the afternoon between 14:00 and 18:00. There is no occupancy during weekends.

Table 1. Building envelope data

\begin{tabular}{cccc}
\hline & Transmittance $\left[\mathrm{W} / \mathrm{m}^{2} \mathrm{~K}\right]$ & Thermal mass $\left[\mathrm{kg} / \mathrm{m}^{2}\right]$ & Area $\left[\mathrm{m}^{2}\right]$ \\
\hline External wall & 0.40 & 373 & 135 \\
Roof & 0.38 & 322 & 200 \\
Ground & 0.42 & 689 & 200 \\
Window & 2.58 & - & 45 \\
\hline
\end{tabular}

The heating system operates from November $15^{\text {th }}$ to March $31^{\text {st }}$ during weekdays (8:00 to 18:00) ensuring $20.0^{\circ} \mathrm{C}\left(+/-0.5^{\circ} \mathrm{C}\right)$ for room air temperature, while it is turned off during the weekends. From June $1^{\text {st }}$ to September $30^{\text {th }}$, the space cooling system is active and the room air temperature is fixed at $26.0{ }^{\circ} \mathrm{C}\left(+/-0.5{ }^{\circ} \mathrm{C}\right)$. Terminal units (fan-coils) working at low temperature are used here to meet space cooling and heating loads. Space cooling and heating demands, which monthly distribution is reported in Figure 1 , are $6,453 \mathrm{kWh}$ and $2,920 \mathrm{kWh}$, respectively. The sanitary hot water demand is not included in this study due to the negligible weight in comparison to space heating demand.

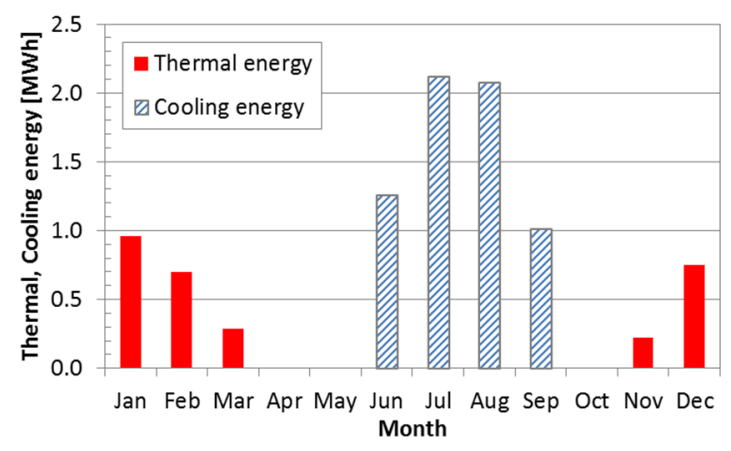

Figure 1. Thermal and cooling demands for each month 
Leaving out Heating, Ventilation and Air Conditioning (HVAC) requirements and in accord with an on-site study carried out on the electric energy required by office buildings [25] electricity demand is evaluated taking into account:

- A demand of $29.64 \mathrm{kWh} / \mathrm{m}^{2}$ on yearly basis considering small power equipment present in the offices (personal computers, printers, monitors, etc.);

- A specific load of $11.74 \mathrm{kWh} / \mathrm{m}^{2}$ per year due to artificial lighting.

The electric loads, leaving out HVAC demand, reported on Figure 2 are considered introducing three type-days (cooling, heating and intermediate season) for weekdays, and only one type-day for weekends.

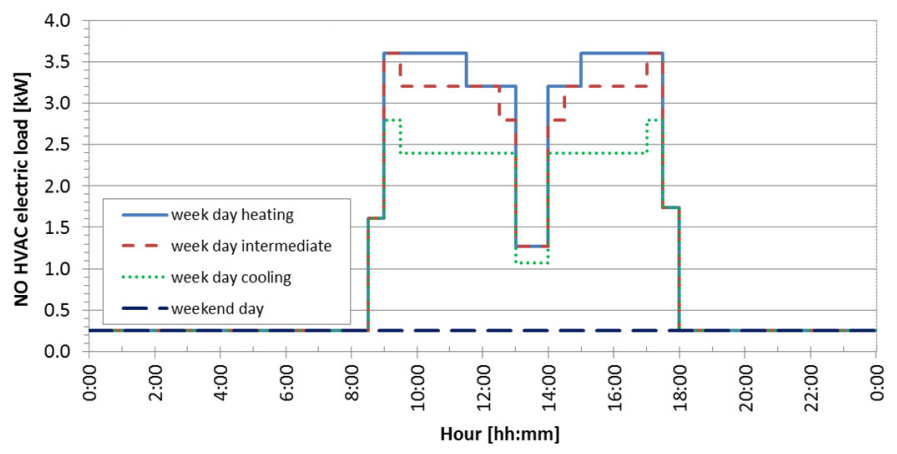

Figure 2. Different electric loads (week days, weekends) excluding HVAC

\section{PROPOSED AND REFERENCE SYSTEM COMPONENTS}

This section describes the main components included in the proposed system and introduced to satisfy energy demand of the analysed user. The main characteristics of a conventional system traditionally considered to satisfy final energy demand of a building, are also described. This premise is fundamental because, by identifying the two compared systems (proposed and reference), it will be possible to evaluate the energy conversion efficiency of each component and therefore the primary energy necessary for its activation. In particular, energy as well as environmental analysis reported in the following paragraphs will be based on the evaluation of energy flows reported on the schemes shown in the following Figure 3 and Figure 4. To meet building space cooling and heating loads an EHP activated by PV plant is introduced here as PS. This PS consists of an EHP, PV modules and a DC/AC inverter. The PV plant meets electricity to activate the EHP and the pure electric load of the office (lighting, small power equipment). The PS is connected to power grid and works with it in bidirectional way.

Two scenarios including PV field were analysed:

- PV-EHP: building electricity requirement is directly met by the PV system and the power grid;

- PV-EHP/EES: electricity load is met by the PV field, that includes also the electric storage battery (EES), and the power grid.

The energy conversion system considered as reference (CS) consists of:

- An electric activated chiller $(\mathrm{CH})$, with an EER equal to 3.0 and a rated cooling power of $13.3 \mathrm{~kW}$;

- A non-condensing gas-fuelled boiler (B) with a thermal efficiency $\left(\eta_{\mathrm{th}}^{\mathrm{B}}\right)$, of $90.2 \%$ and a rated thermal power of $24.0 \mathrm{~kW}$ [Lower Heating Value $(\mathrm{LHV})=$ $9.52 \mathrm{kWh} / \mathrm{Sm}^{3}$ ] analysed in Angrisani et al. [26];

- The power grid meets electric load of the office $(\mathrm{CH}$, lights, small power equipment). The Italian power grid efficiency $\left(\eta_{\mathrm{el}}^{\mathrm{PP}}\right)$ including the thermo-electric power plants, the renewable based power plant contribution, and losses due to distribution and transmission grid is considered equal to 65.5\% [27]. Primary energy is evaluated excluding renewable share and considering only the fossil fuel. 
Figure 3 and Figure 4 show the proposed and conventional systems in heating and cooling modes, respectively.

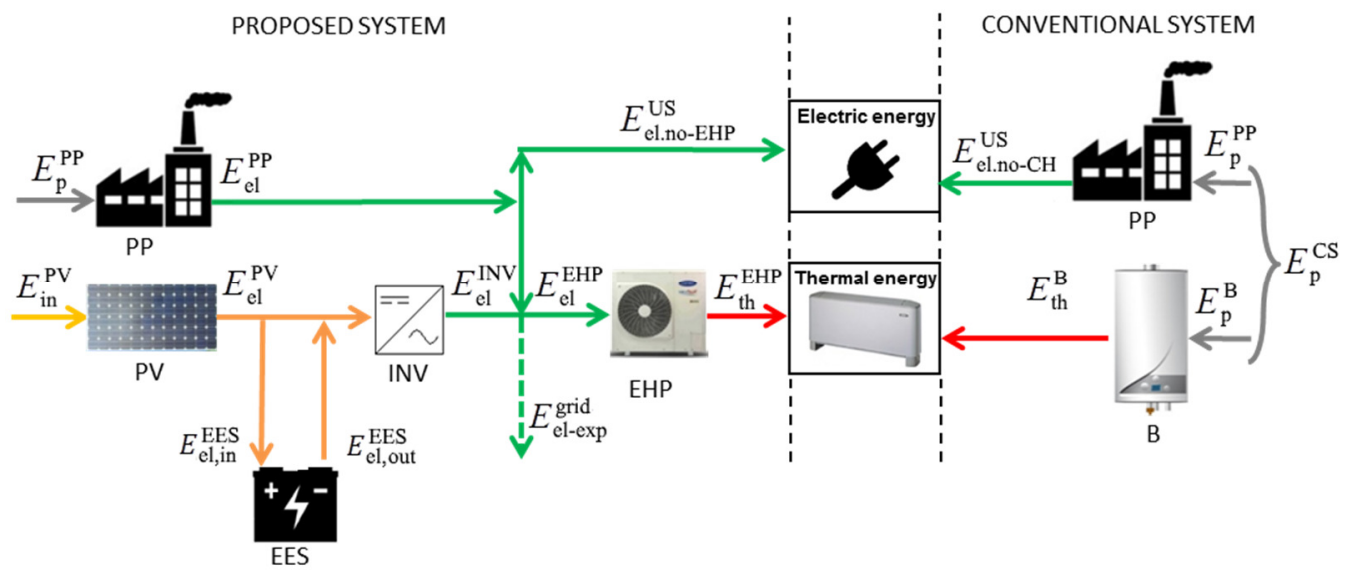

Figure 3. Solar PV and conventional systems in heating period

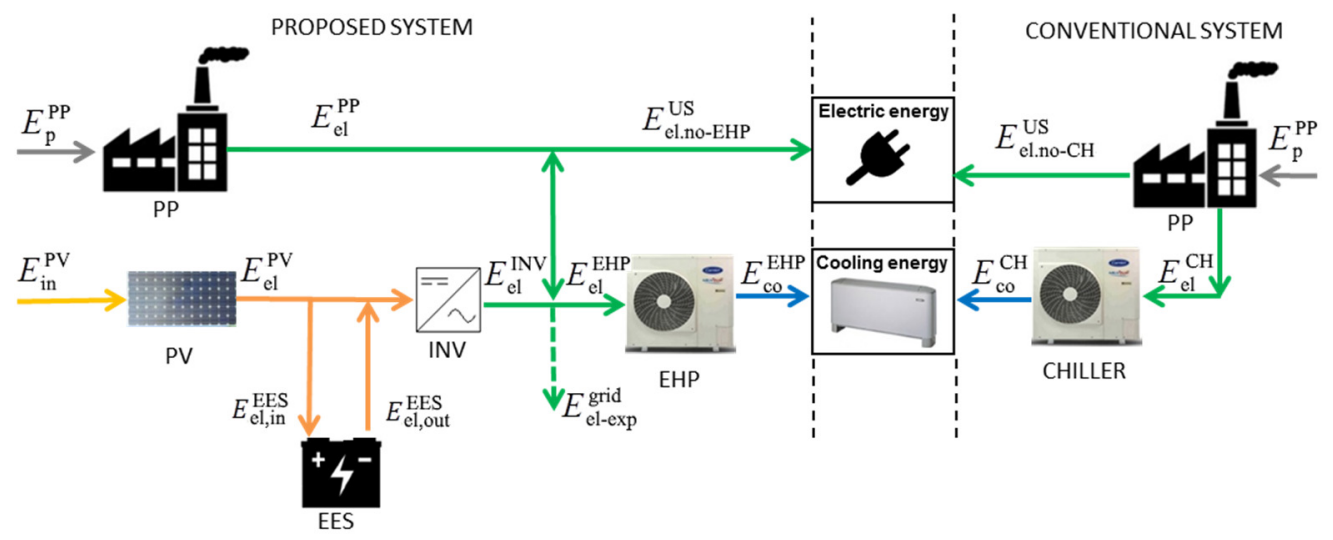

Figure 4. Solar PV and conventional systems in cooling period

To optimize annual electricity production, PV panels facing south have a tilt angle equal to $31^{\circ}$. Furthermore, the analysis was carried out varying the number of solar panels and the peak power (4.5-7.5 kW). Each solar panel has a rated power of $0.25 \mathrm{~kW}$, having a gross area of $1.64 \mathrm{~m}^{2}$ and efficiency in reference test condition of $15.28 \%$. The inverter parameters, different for each peak power, are reported in Table 2.

Table 2. Inverter characteristics

\begin{tabular}{cccc}
\hline PV nominal power [kW] & 4.50 & 6.00 & 7.50 \\
\hline Nominal DC input power [kW] & 5.15 & 6.20 & 7.65 \\
Nominal AC power [kW] & 5.00 & 6.00 & 7.50 \\
Maximum efficiency [\%] & 97.0 & 97.0 & 98.0 \\
EURO/CEC weighted efficiency [\%] & 96.4 & 96.4 & 97.5 \\
\hline
\end{tabular}

The EHP considered for PS has a COP of 3.19 and a rated heating power of $14.1 \mathrm{~kW}$, while it has an EER of 3.32 and a cooling nominal power of $13.3 \mathrm{~kW}$. For the second scenario (PV-EHP/EES) an electric energy storage with three different sizes (3.2, 6.4 and $9.6 \mathrm{kWh}$ ), an efficiency of $94.0 \%$ and a depth of discharge of $90.0 \%$ is added. Electric energy demand per year of PS and CS is reported on Table 3. Total electric consumption depends on pure electric load (artificial lights, small power office equipment), EHP and auxiliaries (fans, circulating pumps, etc.). 
Table 3. Office electric energy demand on annual basis

\begin{tabular}{ccc}
\hline Electricity requirements & PS & CS \\
\hline Small power office equipment [MWh/y] & 5.93 & 5.93 \\
Artificial lights [MWh/y] & 2.35 & 2.35 \\
EHP [MWh/y] & 2.57 & - \\
Chiller [MWh/y] & - & 1.84 \\
HVAC auxiliaries [MWh/y] & 0.79 & 0.79 \\
\hline Total [MWh/y] & 11.6 & 10.9 \\
\hline
\end{tabular}

\section{MODEL DESCRIPTION}

The software introduced for the analysis of the solar based system is TRNSYS 17 [28]. It is usually considered to realize dynamic simulations of energy systems interacting with a building. Each component of the analysed system is characterized through subroutines (types), available in standard and supplementary libraries [29]. The components can be connected to each other to build very complex configurations. Table 4 reports the main components and related types used in TRNSYS project. The 'types' of the most important components are neatly analysed below. PV panels are characterized by 'type 94' [30] that evaluates the current-voltage curves of a single panel starting by an equivalent circuit built considering "four-parameters" available from PV manufacturer data. EHP and $\mathrm{CH}$ are simulated starting by their performance maps (type 941, type 955). Gas-fuelled boiler is modelled using 'type 6', which considers a fixed thermal efficiency. The office building is modelled with 'type 56' which can model the thermal behaviour of a building with different thermal areas.

Table 4. Main components and related types used in TRNSYS

\begin{tabular}{ccc}
\hline Component & Type number & Library \\
\hline PV panel & 94 & Standard \\
Regulator/Inverter & 48 & Standard \\
EES & 47 & Standard \\
EHP & 941 & Standard \\
CH & 655 & Standard \\
Boiler & 6 & Standard \\
Pump & 114 & Standard \\
Multi-zone building & 56 & Standard \\
Pipe/Duct & 31 & Standard \\
Mixing valve & 649 & TESS \\
Diverting valve & 647 & TESS \\
Weather data & 15 & TESS \\
\hline
\end{tabular}

\section{RESULTS}

This paragraph reports the main results obtained on the basis of the methods introduced in the previous paragraph. In particular the analysis is reported considering the proposed system and also comparing this system with the reference one.

\section{Proposed system evaluation: Results}

On the basis of different lay-outs PV plant electric efficiency is $14.6 \%$ if peak power is equal to $4.5 \mathrm{~kW}$ and $6.0 \mathrm{~kW}$, while is $14.7 \%$ for $7.5 \mathrm{~kW}$.

Figure 5 reports on annual basis for each PV power and storage capacity the distribution of electricity due to PV plant (on-site use and exported) and imported from 
electric grid. Electricity from PV is consumed on-site (blue bar) and also feeds the power grid (red bar), while there is an integration from the grid (green bar).

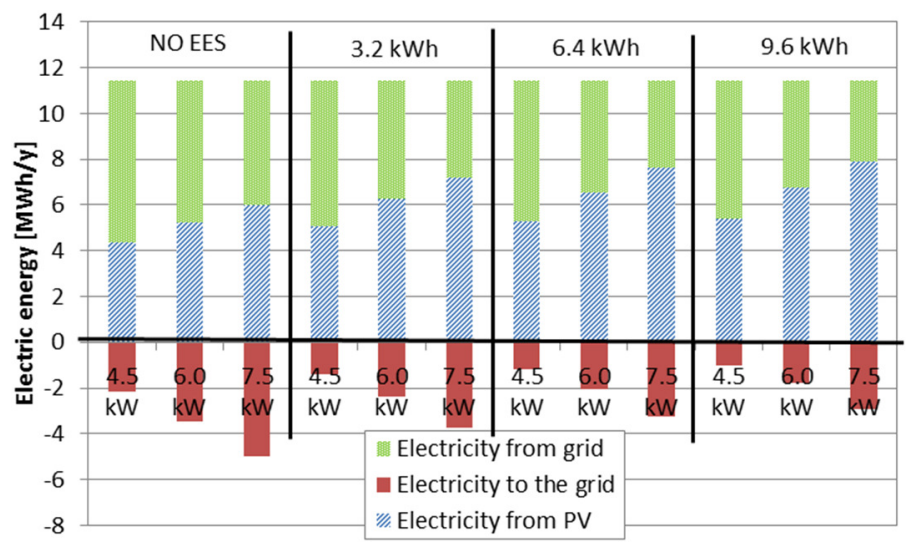

Figure 5. Electric energy distribution as a function of PV rated power and electric storage capacity

In Table 5 the ratios introduced in the previous paragraph, on annual basis and for four configurations, are reported. PV electricity meeting end-user's requirements $(s)$, improves with PV rated power and EES size reaching the best result of 0.681 for $7.5 \mathrm{~kW}$ and $9.6 \mathrm{kWh}$. The fraction of on-site use of PV electricity, with respect to the total production $(d)$, shows a reduction with PV nominal power while it improves with EES capacity. The configuration with the lowest percentage of electricity exported to power grid, equal to $16.0 \%(d=0.840)$, has $4.5 \mathrm{~kW}$ with $9.6 \mathrm{kWh}$ as electricity storage size. A more detailed analysis is reported in Figure 6 that shows on monthly basis the same ratios reported on Table 5 .

For each month, with increasing size of PV plant the weight of on-site use of renewable electricity increases. The introduction of an EES leads to a rise of on-site use of electricity, but this effect is less strong for higher sizes of the battery. The month characterized by the highest contribution of PV electricity on the demand is May, due to high renewable electricity availability and no heating and cooling demands. In winter months low production of PV electricity leads to a strong contribution from external grid up to about $80 \%$ (4.5 $\mathrm{kW}$, January/December, no EES). Electricity sent to the grid improves with PV size, while the addition of an EES leads to a reduction of this effect. Also with reference to $d$ index the addition of an EES improves on-site use of electricity available from PV plant. The highest percentage of electricity exported occurs in intermediate months (April, September), characterized by interesting PV electricity production and no heating and cooling loads.

Table 5. Ratios on annual basis on the on-site use of electric energy available from PV plant

\begin{tabular}{cccc}
\hline PV size $[\mathrm{kW}]$ & Battery capacity $[\mathrm{kWh}]$ & $s[-]$ & $d[-]$ \\
\hline \multirow{4}{*}{4.5} & No EES & 0.375 & 0.669 \\
& 3.2 & 0.437 & 0.786 \\
& 6.4 & 0.454 & 0.818 \\
6.0 & 9.6 & 0.465 & 0.840 \\
\hline \multirow{4}{*}{7.5} & No EES & 0.452 & 0.605 \\
& 3.2 & 0.538 & 0.726 \\
& 6.4 & 0.565 & 0.765 \\
& 9.6 & 0.584 & 0.792 \\
\hline & No EES & 0.518 & 0.548 \\
& 3.2 & 0.618 & 0.659 \\
& 6.4 & 0.656 & 0.702 \\
& 9.6 & 0.681 & 0.730 \\
\hline
\end{tabular}



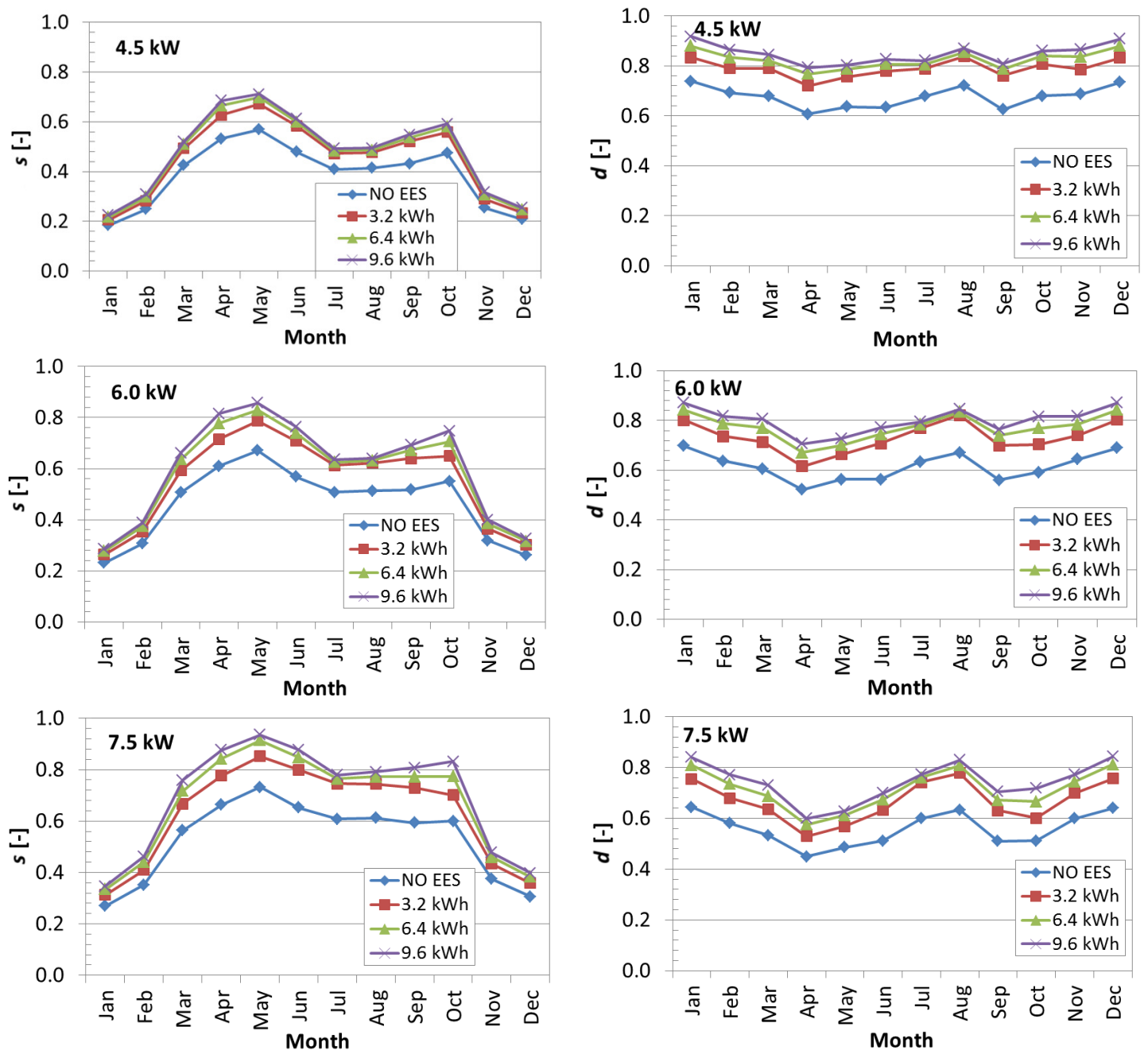

Figure 6. Ratios on monthly basis of on-site use of electricity available from PV plant

\section{Energy and environmental analysis: Results}

As highlighted by Table 6, FESR improves with PV size thanks to the higher availability of renewable electric energy. It ranges between about $59 \%(4.5 \mathrm{~kW})$ and about $93 \%(7.5 \mathrm{~kW}) . \Delta \mathrm{CO}_{2}$ has a behaviour that is in agreement to FESR achieving a peak for each PV power in the configuration without batteries (Table 6). The introduction of electric storage leads to a light reduction, up to about $1 \%$, both for FESR and $\triangle \mathrm{CO}_{2}$ for each peak power. The efficiency of the batteries (94.0\%) leads to worst performance of the proposed system due to the introduction of further losses. Figure 7 reports reference electric efficiency and equivalent $\mathrm{CO}_{2}$ emissions factor on monthly basis with reference to Italian grid. It can be noted that during summer period electric efficiency shows the highest values due to the strong contribution of renewable electricity and in particular from PV. For the same months, of course, equivalent $\mathrm{CO}_{2}$ emission factor reaches the lowest values.

Starting from these parameters an analysis of FESR for PV system without batteries on monthly basis is reported on Figure 8 . Values higher than $100 \%$ depend by PV electricity feeding the grid that for PS in some months is higher that electricity imported from the grid bringing to a negative value for primary energy due to PV-based system [see eq. (3)]. To explain better, the reason why the values could be higher than $100 \%$ the contribution of each term appearing in eq. (3) for configuration without battery and $7.5 \mathrm{~kW}$ is reported in Table 7. Negative values of primary energy due to proposed system $\left(E_{\mathrm{p}}^{\mathrm{PS}}\right)$ correspond to electricity exported to the grid higher than electricity imported from 
the grid. In these cases, the numerator of eq. (1) is higher than denominator leading to a FESR greater than $100 \%$.

Table 6. FESR and $\triangle \mathrm{CO}_{2}$ on annual basis

\begin{tabular}{cccc}
\hline PV power $[\mathrm{kW}]$ & Battery capacity $[\mathrm{kWh}]$ & FESR $[\%]$ & $\Delta \mathrm{CO}_{2}[\%]$ \\
\hline \multirow{3}{*}{4.5} & No EES & 59.2 & 58.4 \\
& 3.2 & 58.9 & 58.0 \\
& 6.4 & 58.7 & 57.9 \\
& 9.6 & 58.6 & 57.7 \\
\hline \multirow{3}{*}{6.0} & No EES & 75.6 & 75.1 \\
& 3.2 & 75.1 & 74.6 \\
& 6.4 & 74.9 & 74.4 \\
7.5 & 9.6 & 74.8 & 74.2 \\
\hline \multirow{3}{*}{7.6} & 92.9 & 92.8 \\
& No EES & 92.4 & 92.2 \\
& 3.2 & 92.1 & 92.0 \\
& 6.4 & 91.9 & 91.7 \\
\hline
\end{tabular}

The highest values, due to exported electricity, are in the months of April and May, characterized by the lack of cooling and heating demands and thus by no HVAC electricity demand. Increasing PV peak power proposed system enhances the electricity exported to the grid and thus the FESR. A similar behaviour found for FESR could be achieved by $\triangle \mathrm{CO}_{2}$. As shown in Table 6 the use of electric storage leads, also on monthly basis, to a light reduction of FESR and $\triangle \mathrm{CO}_{2}$ for each peak power.

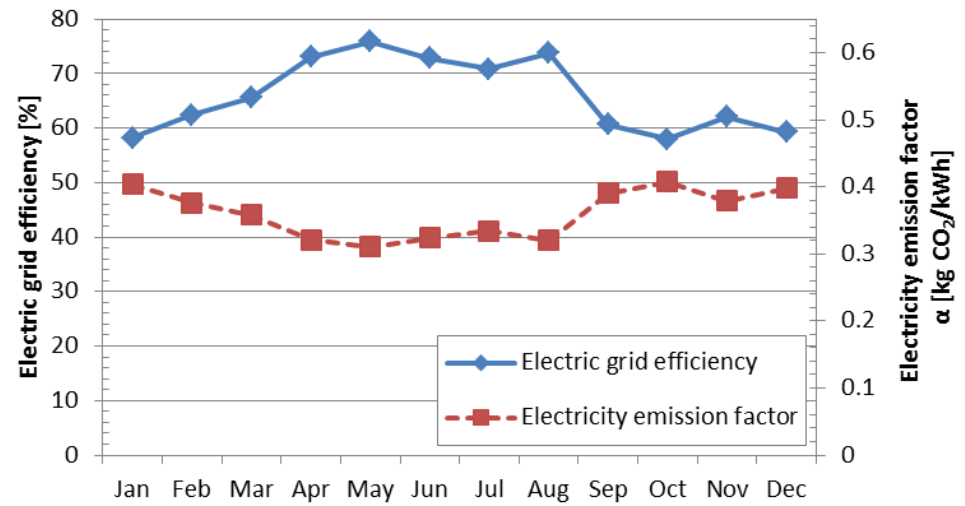

Figure 7. Electric efficiency and equivalent $\mathrm{CO}_{2}$ emission factor for electricity

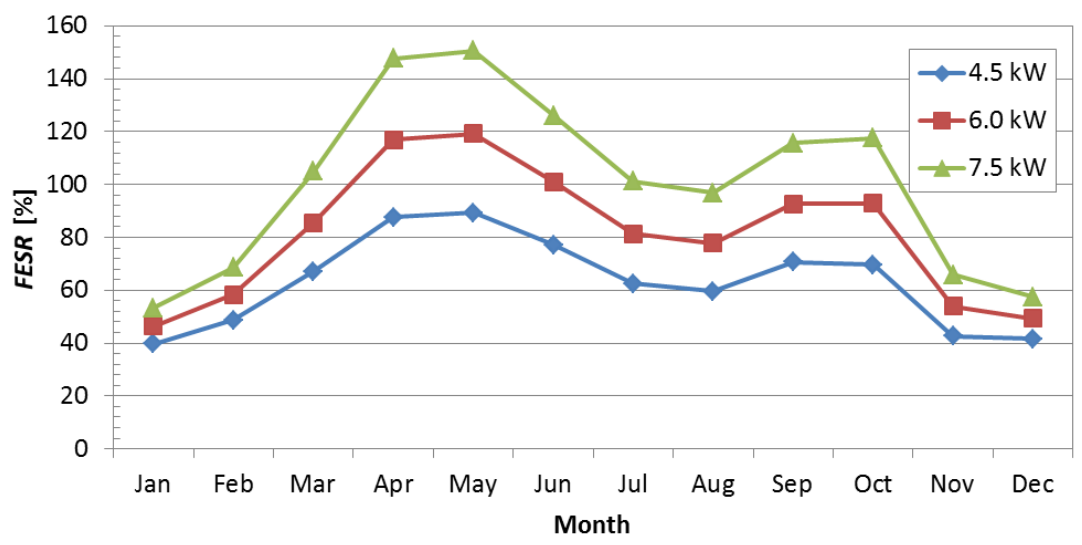

Figure 8. FESR for the PV system without batteries as a function of PV rated power and month 
Table 7. Primary energy due to fossil fuel related to proposed system

\begin{tabular}{ccccccccccccc}
\hline & Jan. & Feb. & Mar. & Apr. & May & Jun. & Jul. & Aug. & Sep. & Oct. & Nov. & Dec. \\
\hline$E_{\mathrm{p}}^{\text {PP }}[\mathrm{kWh}]$ & 1,500 & 1,030 & 581 & 332 & 275 & 461 & 700 & 670 & 585 & 536 & 860 & 1,238 \\
$E_{\mathrm{p}}^{\text {grid }}[\mathrm{kWh}]$ & 305 & 405 & 657 & 802 & 795 & 828 & 724 & 611 & 823 & 771 & 344 & 307 \\
$E_{\mathrm{p}}^{\text {PS }}[\mathrm{kWh}]$ & 1,195 & 625 & -76 & -470 & -520 & -367 & -24 & 58 & -238 & -235 & 516 & 932 \\
\hline
\end{tabular}

\section{CONCLUSIONS}

A solar activated electric, cooling and heating system, consisting of a PV field, an EHP and an electric energy storage, introduced to cover electric, space cooling and heating load of a building used for office purpose is analysed here. Dynamic simulations to assess the energy and environmental indexes of the proposed system modifying PV nominal power are investigated. Two lay-outs (PV-EHP, PV-EHP/EES) were considered by means of parameters evaluating the on-site use of PV electricity, as well as primary energy saving and equivalent $\mathrm{CO}_{2}$ emissions reduction in comparison to conventional reference system. The following results were obtained from the introduction of the proposed system:

- It can be highlighted that on annual basis, PV electricity meeting office demand rises with PV peak power and electric storage capacity, reaching the best result of $0.681(68.1 \%)$ for $7.5 \mathrm{~kW}$ and $9.6 \mathrm{kWh}$. This trend is similar also on monthly basis and in May, due to high PV electricity availability and no heating and cooling loads, the proposed system can cover up $95 \%$ of electric energy demand;

- The electricity feeding the grid increases with PV plant size while showing a reduction with electric storage capacity. The configuration representative of the lowest percentage of exported electricity $(d=0.840)$, is characterized by a PV plant with $4.5 \mathrm{~kW}$ including an electric storage of $9.6 \mathrm{kWh}$. On monthly basis electricity exported is always lower than $50 \%$ if there is a battery;

- In terms of primary energy saving and equivalent $\mathrm{CO}_{2}$ emission reduction, the proposed system always has a better performance than the traditional one, reaching a FESR and $\triangle \mathrm{CO}_{2}$ up to $94 \%$ for PV-EHP lay-out plant and $7.5 \mathrm{~kW}$. On monthly basis the surplus of PV electricity led to FESR and $\triangle \mathrm{CO}_{2}$ higher than $100 \%$ while the worst results appear in winter months (40-60\%).

Different plant layouts could be considered in future works to evaluate how a thermal energy storage (cold, hot water) introduced in the proposed system can improve the performance of the system as proposed by Toradmal et al. [31]. A different way to improve the performance of the system could be the introduction of a demand side management approach to activate the EHP as proposed by Cooper et al. [32]. The proposed methodology could be also extended starting by data on electricity mix of power grid available on hourly basis for different European Countries on ENTSO-E Transparency Platform [33]. A further analysis to evaluate the potentiality of the proposed system could be based on economic indexes. The results could be the basis to evaluate the best support economic schemes to be introduced to support renewable based technologies that are traditionally characterized by high investment costs.

\section{NOMENCLATURE}

\begin{tabular}{|c|c|c|}
\hline $\mathrm{CO}_{2}$ & equivalent dioxide carbon emissions & {$\left[\mathrm{kg} \mathrm{CO}_{2} / \mathrm{y}\right]$} \\
\hline$d$ & $\begin{array}{l}\text { ratio between on-site electricity supplied by photovoltaic } \\
\text { plant to the office and total one available from } \\
\text { photovoltaic plant }\end{array}$ & {$[-]$} \\
\hline$F$ & energy & {$[\mathrm{kWh} / \mathrm{y}]$} \\
\hline & $\begin{array}{l}\text { ratio between on-site use of electricity available from } \\
\text { photovoltaic plant and the total one that office requires }\end{array}$ & {$[-]$} \\
\hline
\end{tabular}




\section{Greek symbols}

$\alpha$

$\beta$

$\eta$

$\Delta \mathrm{CO}_{2}$ emission factor for power grid electricity

emission factor for natural gas

efficiency

avoided equivalent $\mathrm{CO}_{2}$ emissions $\left[\mathrm{kg} \mathrm{CO}_{2} / \mathrm{kWh}_{\mathrm{el}}\right]$

$\left[\mathrm{kg} \mathrm{CO}_{2} / \mathrm{kWh}_{\mathrm{ep}}\right]$

$[-],[\%]$

[\%]

\begin{tabular}{ll}
\multicolumn{1}{c}{ Subscripts } & \\
co & cooling \\
el & electric \\
el-exp & electric exported \\
el,no-CH & electricity excluding chiller requirement \\
el,no-EHP & electricity excluding electric heat pump requirement \\
in & inlet \\
out & outlet \\
p & primary \\
th & thermal
\end{tabular}

\section{Abbreviations}

$\begin{array}{ll}\text { B } & \text { Boiler } \\ \text { CH } & \text { Chiller } \\ \text { COP } & \text { Coefficient Of Performance } \\ \text { CS } & \text { Conventional System } \\ \text { EER } & \text { Energy Efficiency Ratio } \\ \text { EES } & \text { Electrical Energy Storage } \\ \text { EHP } & \text { Electric Heat Pump } \\ \text { EV } & \text { Electric Vehicle } \\ \text { FESR } & \text { Fuel Energy Saving Ratio } \\ \text { HVAC } & \text { Heating and Ventilation Air Conditioning } \\ \text { INV } & \text { Inverter } \\ \text { MPPT } & \text { Maximum Power Point Tracker } \\ \text { PP } & \text { Power Plant } \\ \text { PS } & \text { Proposed System } \\ \text { PV } & \text { Photovoltaic } \\ \text { US } & \text { End user }\end{array}$

\section{REFERENCES}

1. European Commission, Mapping and Analyses of the Current and Future (2020-2030) Heating/cooling Fuel Deployment (fossil/renewables), Work Package 1: Final Energy Consumption for the Year 2012, 2016.

2. Balaras, C. A., Grossman, G., Henning, H. M., Infante Ferreira, C. A., Podesser, E., Wang, L. and Wiemken, E., Solar Air Conditioning in Europe-an Overview, Renewable and Sustainable Energy Reviews, Vol. 11, No. 2, pp 299-314, 2007, https://doi.org/10.1016/j.rser.2005.02.003

3. Angrisani, G., Entchev, E., Roselli, C., Sasso, M., Tariello, F. and Yaïci, W., Dynamic Simulation of a Solar Heating and Cooling System for an Office Building Located in Southern Italy, Applied Thermal Engineering, Vol. 103, pp 377-390, 2016, https://doi.org/10.1016/j.applthermaleng.2016.04.094

4. Del Amo, S. A., Solar Trigeneration: A Transitory Simulation of HVAC Systems Using Different Typologies of Hybrid Panels, Journal of Sustainable Development of Energy, Water and Environment Systems, Vol. 2, No. 1, pp 1-14, 2014, https://doi.org/10.13044/j.sdewes.2014.02.0001 
5. International Energy Agency, Trends 2017 in Photovoltaic Applications, Report IEA PVPS T1-32:2017, 2017.

6. Gestore dei Servizi Energetici, Statistical Report 2016 of Photovoltaic Solar, Report on PV Installations in 2016 (in Italian), Rome, Italy, 2017.

7. Huang, L. and Zheng, R., Energy and Economic Performance of Solar Cooling Systems in the Hot-summer and Cold-winter Zone, Buildings, Vol. 8, No. 37, pp 1-12, 2018, https://doi.org/10.3390/buildings8030037

8. Bilir, L. and Yildirim, N., Photovoltaic System Assessment for a School Building, International Journal of Hydrogen Energy, Vol. 42, No. 28, pp 17856-17868, 2017, https://doi.org/10.1016/j.ijhydene.2017.02.122

9. Solano, J., Olivieri, L. and Caamaño, E., HVAC Systems Using PV Technology: Economic Feasibility Analysis in Commercial Buildings of Ecuador, IEEE Latin America Transactions, Vol. 14, No. 2, pp 767-772, 2016, https://doi.org/10.1109/TLA.2016.7437221

10. Testi, D., Schito, E. and Conti, P., Cost-optimal Sizing of Solar Thermal and Photovoltaic Systems for the Heating and Cooling Needs of a Nearly Zero-Energy Building: The Case Study of a Farm Hostel in Italy, Energy Procedia, Vol. 91, pp 528-536, 2016, https://doi.org/10.1016/j.egypro.2016.06.286

11. Romaní, J., Belusko, M., Alemu, A., Cabeza, L. F., de Gracia, A. and Bruno, F., Control Concepts of a Radiant Wall Working as Thermal Energy Storage for Peak Load Shifting of a Heat Pump Coupled to a PV Array, Renewable Energy, Vol. 118, pp 489-501, 2018, https://doi.org/10.1016/j.renene.2017.11.036

12. Schwarz, H., Schermeyer, H., Bertsch, V. and Fichtner, W., Self-consumption Through Power-to-heat and Storage for Enhanced PV Integration in Decentralised Energy Systems, Solar Energy, Vol. 163, pp 150-161, 2018, https://doi.org/10.1016/j.solener.2018.01.076

13. Carriço, J., Fernandes, J., Fernandes, C. and Branco, P., Technical and Economic Assessment of a $450 \mathrm{~W}$ Autonomous Photovoltaic System with Lithium Iron Phosphate Battery Storage, Journal of Sustainable Development of Energy, Water and Environment Systems, Vol. 6, No. 1, pp 129-149, 2018, https://doi.org/10.13044/j.sdewes.d5.0191

14. Aguilar, F. J., Aledo, S. and Quiles, P. V., Experimental Analysis of an Air Conditioner Powered by Photovoltaic Energy and Supported by the Grid, Applied Thermal $\begin{array}{lllll}\text { Engineering, } \quad \text { Vol. } & 123, & \text { 2017, }\end{array}$ https://doi.org/10.1016/j.applthermaleng.2017.05.123

15. Roselli, C., Sasso, M. and Tariello, F., Dynamic Simulation of a Solar Electric Driven Heat Pump for an Office Building Located in Southern Italy, International Journal of Heat and Technology, Vol. 34, No. 2, pp S496-S504, 2016, https://doi.org/10.18280/ijht.34S243

16. Roselli, C., Sasso, M. and Tariello, F., Dynamic Simulation of a Solar Electric Driven Heat Pump Integrated with Electric Storage for an Office Building Located in Southern Italy, International Journal of Heat and Technology, Vol. 34, No. 4, pp 637-646, 2016, https://doi.org/10.18280/ijht.340413

17. Roselli, C. and Sasso, M., Integration Between Electric Vehicle Charging and PV System to Increase Self-consumption of an Office Application, Energy Conversion and Management, Vol. 130, pp 130-140, 2016, https://doi.org/10.1016/j.enconman.2016.10.040

18. Roselli, C., Sasso, M. and Tariello, F., Integration Between Electric Heat Pump and PV System to Increase Self-consumption of an Office Application, Renewable Energy and Environmental Sustainability, Vol. 2, No. 28, p 6, 2017, https://doi.org/10.1051/rees/2017038

19. Hartmann, N., Glueck, C. and Schmidt, F. P., Solar Cooling for Small Office Buildings: Comparison of Solar Thermal and Photovoltaic Options for Two Different 
European Climates, Renewable Energy, Vol. 36, No. 5, pp 1329-1338, 2011, https://doi.org/10.1016/j.renene.2010.11.006

20. Izquierdo, M., de Agustìn-Camacho, P. and Martin, E., A Micro Photovoltaic-heat Pump System for House Heating by Radiant Floor: Some Experimental Results, Energy Procedia, Vol. 48, pp 865-875, 2014, https://doi.org/10.1016/j.egypro.2014.02.100

21. Izquierdo, M. and de Agustìn-Camacho, P., Solar Heating by Radiant Floor: Experimental Results and Emission Reduction Obtained with a Micro-photovoltaic-heat Pump System, Applied Energy, Vol. 147, pp 297-307, 2015, https://doi.org/10.1016/j.apenergy.2015.03.007

22. Huang, B.-J., Hou, T.-F., Hsu, P.-C., Lin, T.-H., Chen, Y.-T., Chen, C.-W., Li, K. and Lee, K. Y., Design of Direct Solar PV Driven Air Conditioner, Renewable Energy, Vol. 88, pp 95-101, 2016, https://doi.org/10.1016/j.renene.2015.11.026

23. Weniger, J., Tjaden, T. and Quaschning, V., Sizing and Grid Integration of Residential PV Battery Systems, Energy Procedia, Vol. 46, pp 78-87, 2014, https://doi.org/10.1016/j.egypro.2014.01.160

24. Istituto Superiore per la Protezione e la Ricerca Ambientale (ISPRA), $\mathrm{CO}_{2}$ Emission Factors in Electricity Sector and Analysis of Emissions Decomposition, Rome, Italy, 2015, http://www.isprambiente.gov.it/files/pubblicazioni/rapporti/R_212_15.pdf, [Accessed: 15-October-2018]

25. Menezes, A. C., Cripps, A., Buswell, R. A., Wright, J. and Bouchlaghem, D., Estimating the Energy Consumption and Power Demand of Small Power Equipment in Office Buildings, Energy and Buildings, Vol. 75, pp 199-209, 2014, https://doi.org/10.1016/j.enbuild.2014.02.011

26. Angrisani, G., Minichiello, F., Roselli, C. and Sasso, M., Experimental Investigation to Optimise a Desiccant HVAC System Coupled to a Small Size Cogenerator, Applied Thermal Engineering, Vol. 31, No. 4, pp 506-512, 2011, https://doi.org/10.1016/j.applthermaleng.2010.10.006

27. TERNA, Statistics and Forecasts, Statistical Data, Rome, Italy, 2015, https://www. terna.it/en-gb/sistemaelettrico/statisticaldata.aspx, [Accessed: 15-October-2018]

28. TRNSYS v. 17.01.0025, TRaNsientSYstem Simulation Program, Solar Energy Laboratory, University of Wisconsin-Madison, Madison, Wisconsin, USA, 2010.

29. TESS Component Libraries v.17.01 for TRNSYS v17.0 and the TRNSYS Simulation Studio, Parameter/Input/Output Reference Manual, Thermal Energy System Specialists, LLC, Madison, Wisconsin, USA, 2004.

30. Mazzeo, D., Matera, N., Bevilacqua, P. and Arcuri, N., Energy and Economic Analysis of Solar Photovoltaic Plants Located at the University of Calabria, International Journal of Heat and Technology, Vol. 33, No. 4, pp 41-50, 2015, https://doi.org/10.18280/ijht.330406

31. Toradmal, A., Kemmler, T. and Thomas, B., Boosting the Share of Onsite PV-electricity Utilization by Optimized Scheduling of a Heat Pump Using Buildings Thermal Inertia, Applied Thermal Engineering, Vol. 137, pp 248-258, 2018, https://doi.org/10.1016/j.applthermaleng.2018.03.052

32. Cooper, S. J. G., Dowsett, J., Hammond, G. P., McManus, M. C. and Rogers, J. G., Potential of Demand Side Management to Reduce Carbon Dioxide Emissions Associated with the Operation of Heat Pumps, Journal of Sustainable Development of Energy, Water and Environment Systems, Vol. 1, No. 2, pp 94-108, 2013, https://doi.org/10.13044/j.sdewes.2013.01.0007

33. ENTSO-E Transparency Platform, https://www.entsoe.eu, [Accessed: 15-October-2018] 